\title{
DEFERÊNCIA JUDICIAL PARA COM AS ESCOLHAS ADMINISTRATIVAS: RESGATANDO A OBJETIVIDADE COMO ATRIBUTO DO CONTROLE DO PODER
}

\author{
JUDICIAL DEFERENCE TO ADMINISTRATIVA CHOICES: RESCUING OBJECTIVITY
}

AS A FEATURE IN POWER CONTROL

Pós-doutorado em Administração Regina Lírio do Valle Pós-doutorado em Adreito pela Universidade Gama Filho (2006), Mestrado em Direito pela Universidade Estácio de Sá (2003), Especialização em VIII Cursos de Enero pela Universidad San Pablo (2006), Especialização Jurisdición Constitucional pela Universidad Carlos III de Madrid - Instituto de Derecho Publico Comparado (2006), Professora do Programa de PósGraduação em Direito da UNESA/RJ.

\begin{abstract}
Resumo
A judicialização incremental das escolhas públicas trazida por uma Constituição comprometida com a aplicação de direitos humanos abre o sistema a uma subjetividade indesejada entre os agentes investidos de função de controle - nisto se incluindo julgadores. Este artigo tem por objetivo propor um novo conceito de deferência para com as escolhas administrativas antecedidas de planejamento como critério a orientar a adjudicação. A proposição se faz a partir de pesquisa documental e bibliográfica. Tem-se em conclusão que a análise deferente exige conhecimento do curso de ação administrativa objeto de controle judicial; verificação de que o curso de ação desenhado esteja sendo efetivamente implementado; e um exercício dialógico com a racionalidade administrativa quando da impugnação das escolhas públicas. A proposta se alinha com a necessária consideração das capacidades institucionais e efeitos dinâmicos da decisão judicial pretendida; ela igualmente incrementa a justificação, como atributo necessário não só à adjudicação, mas também à anterior escolha administrativa.
\end{abstract}

Palavras-chave: capacidades institucionais, deferência judicial, escolhas públicas, políticas públicas

\begin{abstract}
The incremental judicialization on public choices brought by a constitution committed with human rights application opens the system to a pervasive and undesired subjectivity among agents invested with controlling functions - judges included. This article aims to propose a new concept of deference as criteria to orient adjudication, departing from a documental and bibliographic
\end{abstract}


review. The deferential judicial approach on public choices requires awareness of the administrative course of action allegedly scrutinized in the lawsuit; ascertainment that the course of action is being effectively implement; and a dialogical performance with the administrative reasoning in challenging that same public choice. The proposal aligns with the necessary consideration of institutional capacities and dynamic effects of the intended ruling; it also enhances justification, as a necessary feature not only in adjudication, but also in the prior public choice.

Key-words: Institutional capacities, judicial deference, public choices, public policies

\section{CONSIDERAÇÕES INICIAIS}

Trinta anos de aplicação do Texto Fundamental tornaram a crítica às escolhas públicas um lugar comum na rotina forense, com a constante reconfiguração judicial destas mesmas opções, seja no plano de decisões dizendo respeito diretamente à esfera individual de direitos, seja naquela do desenho de macro estratégias de ação estatal.

O objeto do presente texto é o delineamento de um conceito de deferência judicial para com as escolhas administrativas - sua configuração no período anterior à Carta de Outubro, e seu lugar no sistema de controle do poder que esse mesmo Texto inaugurou. O objetivo é examinar a viabilidade constitucional de se prescrever essa mesma atitude como critério possível de equacionamento da crítica judicializada às opções administrativas, quando se tenha estas precedidas do dever de planejamento.

O ponto de partida é a problemática associada à (possível) perda de referenciais objetivos para o desenvolvimento do controle judicial da ação administrativa. Ampliada a esfera de investigação judicial pela conjugação da aplicação imediata dos direitos fundamentais e interpretação amplíssima da garantia constitucional de acesso à justiça, tem-se um incremento exponencial das demandas envolvendo a impugnação de escolhas públicas. O critério de análise, à vista da indeterminação de conteúdo destes mesmos direitos, por vezes resvala para apreciações subjetivas, com o uso retórico de cláusulas gerais como a proteção à dignidade da pessoa, ou ainda proporcionalidade e razoabilidade. Investiga-se neste 
texto a possibilidade de resgate da deferência como parâmetro possível à orientação desta mesma atividade judicante. A hipótese é de que essa matriz de aproximação $a b$ initio deferente, além de prestar reverência ao dever de motivação contido no art. 93, IX CF; pode ainda favorecer o aperfeiçoamento da ação pública, e ao mesmo tempo, evitar a transferência de juízos discricionários que são próprios à Administração, aos agentes de controle.

Este artigo expressa uma pesquisa ainda em desenvolvimento, construída a partir do método crítico dialético, tendo por base fontes doutrinárias e documentais, nacionais e estrangeiras.

O texto se desenvolverá em cinco partes. As considerações iniciais da Parte 1 localizam a problemática, objeto, objetivo e demais elementos metodológicos. A Parte 2 explora a presença da ideia da deferência para com as escolhas administrativas no período anterior à Carta de 1988 - então veiculada especialmente através da proclamada insindicabilidade do mérito administrativo. Prevalecia a lógica do reconhecimento da existência de uma esfera inteiramente blindada ao controle das escolhas administrativas. Ante o predomínio da legalidade estrita, o limitado espaço remanescente de juízo discricionário era tido como reserva absoluta da Administração, insuscetível de apreciação judicial. A Parte 3 enuncia a proposta da deferência para com as escolhas administrativas antecedidas de planeamento como aproximação aplicável sob a égide da Carta de 1988, quando os compromissos valorativos não mais permitem o reconhecimento apriorístico de uma área de nãocontrole, especialmente de cariz judicial. Apresentam-se os três componentes da deferência como critério orientador da atividade judicante de crítica à ação administrativa; tudo no rumo da valorização da racionalidade administrativa e da objetivação do controle. Finalmente, na Parte 4 se expõe como fundamento à proposta, também a questão relacionada à necessária observância da capacidade institucional da Administração Pública, e ao resgate do dever de justificação na atuação de todos os agentes envolvidos na formulação e controle das escolhas públicas. A parte 5 indica etapa subsequente do esforço de pesquisa que está ainda em curso.

A complexificação das sociedades, e por via de consequência, da ação dos agentes de ordenação do convívio coletivo vem exigindo da ciência do direito a busca de formulações que descartem os esquemas simplificadores e as soluções binárias. Isso envolve necessariamente uma sofisticação no debate, e acima de tudo, o 
incremento do ônus argumentativo dos envolvidos, especialmente quando o dissenso se veicula no leito do controle jurisdicional. Não há posições aprioristicamente preferenciais, nem instâncias de poder a quem a Constituição reconheça qualquer signo de favoritismo em abstrato. O sistema se constrói a partir da autoridade do argumento - e não do argumento de autoridade. Esse o principal consectário de se viver num Estado que é de Direito - mas que há de se demonstrar receptivo ao exercício de argumentação e persuasão, como é próprio do ambiente que também ex vi constituitionis, se tem por democrático.

\section{DEFERÊNCIA PRÉ-CONSTITUIÇÃO, E A RECONFIGURAÇÃO DESTA LÓGICA PELA INCORPORAÇÃO PELO TEXTO FUNDANTE DE COMPROMISSOS FINALÍSTICOS AO ESTADO}

A ideia central subjacente ao conceito de deferência, inclusive judicial entendida no seu sentido coloquial, como atitude de respeito e consideração - para com as escolhas da Administração Pública já se tinha presente em sede doutrinária no período que antecede à chamada Constituição-Cidadã. Ainda que a expressão em si não se enunciasse nos compêndios, suas manifestações se tinha, por exemplo, na proclamação dos efeitos jurídicos da presunção de legalidade, legitimidade e veracidade dos atos administrativos, a saber, a inversão do ônus da prova. Em especial, a noção da insindicabilidade do mérito administrativo sintetizava no período pré-Constituição de 1988, o reconhecimento da existência de um campo imune à investigação judicial - e portanto, uma deferência no grau máximo, bloqueadora de qualquer análise. À época, o respeito à alternativa eleita pela Administração Pública se punha como cláusula de proteção em abstrato às preferências por ela manifestas, reduzindo o controle judicial aos aspectos tão somente de ordem formal, restando indene a dimensão substantiva da opção administrativa.

De outro lado, reconhecido à Administração um espaço de escolhas não parametrizadas por lei - discricionárias - tinha-se a proclamação de intangibilidade dessas mesmas opções, que consistiriam o mérito da escolha administrativa. Abdicando a lei da predeterminação de conteúdo da escolha, e tendo-se presente a Administração Pública como agente a empreender à eleição da alternativa; disso decorria a blindagem para fins de controle, para com opção por ela formulada. $\mathrm{O}$ atributo estava fortemente associado ao sujeito; ao autor das escolhas (Estado- 
Administrador) - e não ao seu conteúdo propriamente.

Observe-se que o modelo não se distanciava, a rigor, da opção manifesta pela Suprema Corte americana na mesma temática da deferência, na análise do caso Chevron (USA, Supreme Court, 1985) - paradigma de critério de controle judicial das escolhas administrativas manifestas pelas agências reguladoras naquele país. Também ali, empreendida a deliberação legislativa de não dispor especificamente sobre determinada matéria ${ }^{1}$, ou de transferir a sua regulação à entidade administrativa, abre-se espaço à deferência para com a escolha empreendida pelo Estado Administrativo, desde que esta represente uma construção razoável do sentido do comando legislativo silente ou ambíguo. Uma vez exercida a delegação segundo os limites de competência em favor da agência fixados na lei (ainda que de forma ambígua), ver-se-ia a escolha administrativa formulada pela agência, infensa a um controle judicial substantivo (HASEN, 2000). O critério, também lá, se refere à competência e ao elemento subjetivo (presença da Administração como formulador da escolha), em reverência ao direcionamento que o Congresso empreendeu da matéria ao Executivo (SCALIA, 1989, p. 516).

Essa matriz de análise cunhada sob a ordem constitucional anterior, centrada exclusivamente na presença do agente Administração, e que identificava a deferência com a vedação ao exercício do controle, inclusive o judicial, não sobrevive na sua inteireza, à promulgação da Constituição de 1988 - e por várias razões.

A primeira delas reside na circunstância de que um ambiente democrático tende a rejeitar preferências relacionadas exclusivamente à presença de um determinado sujeito. Isso porque neste modelo, a simples imputação subjetiva da escolha culminaria no esvaziamento da deliberação democrática - o que evidentemente não se coaduna com o presente estágio de Estado pós-moderno². Afinal, a presença do sujeito Administração Pública, nesta concepção antes havida (e hoje superada), qualificaria a opção por ela empreendida, não porque esta tenha sido formulada de maneira satisfatória a ver da maioria; mas porque a intervenção do sujeito " $x$ " por si só se revelaria apta a conferir o atributo de adequação ou

\footnotetext{
1 Naquela experiência alienígena, tanto o silêncio da lei, quanto a ambiguidade na definição da competência para a normatização infra legal se tinha por deliberação legislativa em favor da estrutura administrativa (agência).

2 Examinando a redefinição dos liames políticos que se põe na pós-modernidade, Chevallier alude a uma democracia alargada, que extrapola os limites da simples representação para acolher a ampliação do momento deliberativo como garantia de legitimidade (CHEVALLIER, 2009, p. 224).
} 
insindicabilidade da opção formulada (BANDEIRA DE MELLO, 1992, p. 47).

Some-se ainda a intensificação do sistema de controle trazida pela Carta de 1988 como mecanismo também de garantia de fidelidade a seus compromissos finalísticos. Numa ordem constitucional onde se tem clara orientação axiológica do poder a partir da fixação expressa de objetivos fundamentais à República, e numa realidade fática em que se amplia progressivamente o espectro de escolhas discricionárias confiadas ao Estado, a lógica da insindicabilidade por força da presença do sujeito Administração Pública coartaria o controle de maneira incompatível com o projeto fundante.

Sob a égide da Constituição de 1988, tem-se que o signo de legitimidade da ação estatal passa a repousar na sintonia entre o seu agir e os propósitos constitucionais a ele traçados. ${ }^{3}$ Desloca-se o lugar de apuração do alinhamento com a dimensão substantiva da democracia - portanto, da legitimidade da ação estatal do momento de formulação em si da escolha pública, em que se identificava quem o seu autor; para aquele posterior a ela, onde se afere sua sintonia com os propósitos constitucionais na sua concepção em abstrato, e ainda na sua execução em concreto. Legitima-se a escolha pública pelos seus resultados (MOREIRA NETO, 2006); logo, o critério não comporta mais um modelo puramente formal, que se dê por satisfeito com a presença da Administração Pública como sujeito. Ao contrário, impositivo o ingresso do elemento substantivo no exercício do controle do poder, por qualquer das estruturas a isso incumbidas.

Inequívoco ainda o elemento histórico e sociológico. Redemocratizado o país, inevitável o repúdio às escolhas estatais blindadas ao controle. Se democracia, como apontava Bobbio (2000, p. 386), é poder em público; isso assim se dá para viabilizar a sindicância das escolhas deste mesmo poder. De outro lado, a afirmação de que ainda existem opções discricionárias abertas ao administrador se vê objeto de uma espécie de contaminação por incidentes pretéritos, com uma carga semântica para alguns ainda negativa, onde se associa discricionariedade a arbítrio e excesso (SUNDFELD, 2014, p. 238-239). Tem-se então a rejeição à discricionariedade administrativa, no discurso e na prática da impugnação judicial - estratégia cujo resultado final, a rigor, é a transferência destas mesmas escolhas discricionárias, da

\footnotetext{
3 É de Moreira Neto (2016, p. 76-77) o apontamento de que a dimensão substantiva da democracia se traduz não no método de deliberação coletiva, mas na "exigência de resultados coerentes com os valores que a informam".
} 
Administração para as instâncias controladoras (MARQUES NETO, 2010).

É nesse movimento de afirmação da orientação finalística da Administração Pública que perde força a ideia da deferência para com as escolhas administrativas, substituída pela percepção de ampla sindicabilidade destas mesmas opções. Observe-se que nenhuma contradição existe nesse duplo movimento: constrita a escolha administrativa pelos compromissos axiológicos, é natural que o exercício do controle ganhe nova impulso, vocacionado a fazer valer essa mesma limitação. Num ambiente de intensificação da judicialização da vida (BARROSO, 2012), o resultado é a transposição para a seara deste mesmo poder, do debate em torno da adequação das opções estratégicas da Administração Pública nos mais variados temas. Tudo se discute a partir de uma retórica de desqualificação das estratégias administrativas eleitas, tidas por aprioristicamente inadequadas por despreparo ou contaminação político-partidária de seus formuladores.

Transitando de um extremo ao outro - da legitimação exclusivamente pelo sujeito, para a deslegitimação retórica e apriorística que advém da presença desse mesmo sujeito - tem-se quando menos, o risco de perda, no processo de formulação das escolhas públicas, da particular aptidão técnica reconhecida à Administração, e determinante na origem, do arquétipo institucional de repartição de funções em braços especializados. Mais ainda, abre-se espaço ao exercício de uma função de controle que não se veja guiada por critérios objetivos. Afinal, no caminho da determinação do conteúdo da ação estatal tem-se necessariamente a atividade de densificação dos deveres constitucionais de ação - e isso se deve verificar não a partir de um esquema subssuntivo, mas sim de formulação de escolhas estratégicas. Em resumo; a partir de um processo decisório que sofre sim, influxos técnicos, mas também inputs originários da política - o que tematiza a relevância de ter-se em conta as escolhas dos agentes investidos desta particular legitimidade.

A virtude, como se sabe, não repousa nos extremos. Se o reconhecimento de uma liberdade plena ao administrador para a formulação de escolhas públicas insuscetíveis de controle se afigura quando menos perigoso (se não arbitrário); a transposição de juízos de conveniência e oportunidade para as estruturas de controle se apresenta como alternativa antidemocrática. A mesma Constituição que confere direitos, cria também as estruturas (instituições) vocacionadas à sua (projeto transformador nela veiculado) implementação. Ora, se outra instituição age substitutivamente, tem-se aí também infidelidade constitucional. O resultado é uma 
prática institucional controladora que, em nome de defender a Constituição, viola à Constituição. É no esforço de afastamento das escolhas puramente subjetivas - seja da Administração, seja daquelas dos integrantes do sistema de controle ${ }^{4}$ - que se retoma a ideia da deferência para com as escolhas administrativas antecedidas do dever de planejamento como critério orientador da indispensável dimensão da sindicância das opções públicas.

\section{DEFERÊNCIA COMO ABERTURA COGNITIVA ÀS RAZÕES DA ADMINISTRAÇÃO: UM ACORDO SEMÂNTICO}

O critério da deferência - como já se teve oportunidade neste mesmo texto de apontar - é elemento presente em vários sistemas administrativos do mundo, determinando distintos graus na intensidade do controle judicial. Uma doutrina de deferência envolve a definição de um tipo de relação ou aproximação desenvolvida pelo controle judicial para com uma escolha administrativa submetida ao crivo. $\mathrm{Na}$ experiência internacional, múltiplas são as tentativas de parametrização dessa atividade judicante, muitas vezes construídas a partir de categorias formais. O recurso a uma cisão entre questões de competência e de substância; à evocação da delegação legislativa implícita ou ainda uma distinção entre espécies de discricionariedade (administrativa ou técnica); todos estes são modelos aplicados em terras alienígenas. ${ }^{5}$

Em que pesem os benefícios em tese da criterização prévia da decisão judicial como exercício de objetivação desta mesma análise, não se pode deixar de ter em conta, em tempos de hipermodernidade (DROMI, 2005, p. 21-22), que dificilmente se logrará o delineamento de um critério formal abstratamente construído que seja igualmente aplicável ao controle de qualquer das escolhas administrativas.

As opções explicativas dos modelos de deferência aplicados em terras estrangeiras gravitam, em última análise, em torno de argumentos de capacidade institucional, aplicando-se a deferência sempre que se avance no exame daquilo que

\footnotetext{
${ }^{4}$ Não é ocioso referir que o problema da subjetividade no exercício da delimitação de valores abstratos na aplicação das normas de direito público adquiriu relevância tal que impulsionou a promulgação da Lei 13.655/18, endereçando-se expressamente não só à Administração Pública, mas também a controladores e ao Poder Judiciário.

${ }^{5}$ Para uma detalhada análise de modelos alienígenas de controle judicial da Administração Pública, com a aferição do papel da deferência em cada qual deles, consulte-se MORAES (1999); e mais recentemente, JORDÃO (2016).
} 
se considera a essência do desenvolvimento da atividade administrativa - seja por se cuidar de escolha substantivamente administrativa, seja pela existência expressa ou implícita de delegação legislativa, seja por se adentrar ao domínio da expertise técnica que, mais uma vez, se reconhece como inerente em princípio, à Administração Pública. Em qualquer delas, tem-se pouca abertura à discussão substantiva da opção administrativa, eis que a aptidão institucional se oporia como limite, presumindo-se assim o acerto da escolha empreendida pela estrutura institucional concebida especificamente para essa atividade reguladora.

A opção que se empreende neste trabalho preconiza a deferência não a partir do reconhecimento em abstrato de especial capacidade institucional. O que se propõe é uma matriz de controle que some a este componente o elemento máximo evidenciador dessa mesma aptidão estrutural, que é identificação e publicização da racionalidade subjacente à escolha; racionalidade essa que se identifica como resultado da observância ao dever de planejamento. Deferência, nos termos que ora se propõe, se aplica numa prática orientada ao diálogo, desenvolvido a partir de uma dialética entre Administração Pública e agentes de controle presidida por argumentos objetivos e conhecidos. Incorpora-se uma percepção de arquitetura dos poderes que encontrará neste diálogo, o caminho para a construção de relações que invistam menos na separação, e mais na harmonia entre os poderes.

A proposta é de compreender-se deferência como atributo determinante de três distintos efeitos sobre a função judicante: $1^{\circ}$ ) determina o dever do controlador de conhecer os termos da opção administrativa que seja objeto de crivo; $\left.2^{\circ}\right)$ determina ainda ao controlador aferir se a escolha administrativa está sendo executada como formalmente enunciada - e se não está, quais os motivos da modificação; e $3^{\circ}$ ) determina o dever de que a impugnação à opção administrativa se desenvolva a partir de uma relação dialética para com as razões oferecidas pela Administração para a eleição daquela específica trilha de ação.

Não se está, na abordagem ora apresentada, a delimitar territórios; a desenhar fronteiras dentro das quais se tenha possível ou não o controle. A lógica não é de cunhagem de uma cláusula de bloqueio fechada - mas de abertura a um juízo crítico informado e dialético.

\subsection{Deferência como nivelamento cognitivo}


No primeiro momento da aplicação do proposto critério de deferência, tem-se a indagação acerca do conteúdo específico da estratégia de ação desenhada pela Administração - seja quando se está a desenvolver o controle em abstrato da ação administrativa naquilo que se denomina controle judicial de políticas públicas; seja quando se cuida da sindicância dos efeitos desta mesma ação sobre a esfera individual de direitos de um determinado cidadão. O pressuposto é de que, excluída como possibilidade a ação administrativa despida de intencionalidade e orientação finalística; este mesmo elemento objetivo de direcionamento da ação estatal é de ser conhecido e declinável de molde a que se possa (justamente) desenvolver o controle de sua compatibilidade para com os compromissos finalísticos postos pela Constituição.

Significa dizer que deflagrada a iniciativa de controle judicial, a primeira investida do agente controlador é de ser no sentido de conhecer os termos da estratégia desenhada pela Administração Pública para o trato da matéria. Existe uma política pública em curso? Quais os seus termos? Ela foi aplicada à hipótese? A alegada violação a direito decorre da estrita aplicação à esfera individual dessa mesma política pública? Ou a hipótese de fato contempla uma simples falha de serviço, com a não aplicação da estratégia de ação que o Estado traçara para si? Ou ainda, o que se tem é uma situação individual ou coletivo que se julga erroneamente excluída da política pública existente e em curso?

Na eventualidade desse tipo de informação não se ter trazida espontaneamente pela Administração Pública, incumbe ao controlador buscar junto a ela esses mesmos dados, inclusive com os eventuais meios de constrição de que disponha 6 . A investigação neste plano é de natureza puramente factual; busca-se conhecer qual a racionalidade determinante da (in)ação administrativa, ainda sem qualquer aferição quanto à sua adequação substantiva.

Observe-se que este primeiro estágio da deferência exigirá da Administração Pública uma mudança de paradigma, eis que não obstante os reclamos do princípio da publicidade, doutrinariamente atualizado para compreender um dever constitucional de transparência; fato é que as estruturas administrativas têm frequente

\footnotetext{
${ }^{6}$ Tenha-se em conta que a inação administrativa apontada na demanda (quem litiga, o faz porque não alcançou algo que julga lhe seja devido) pode materializar uma opção expressa por não atuar; ou pode ainda traduzir um recorte da escolha administrativa que excluiu dentre seus destinários, àqueles de perfil idêntico ao do litigante.
} 
dificuldade, quando não resistência no declínio de suas razões de agir.

Muitas são as hipóteses explicativas para esse padrão de comportamento da Administração Pública, mas pelo menos duas delas merecem destaque: 1) o frequente uso do chamado conhecimento tácito; e 2) o temor de um juízo negativo de agentes controladores quando a escolha administrativa se dá a partir de cenários parciais ou de soluções provisórias, no mais das vezes, sabidamente experimentais.

No plano do conhecimento tácito, o fenômeno, a rigor, não é exclusivo da Administração Pública, mas inerente ao comportamento humano. A reiteração de práticas culmina por determinar uma automatização que dissocia o agir das suas razões determinantes originais. No âmbito dos órgãos públicos, a manifestação clássica do conhecimento tácito é a imputação da prática ao "...tempo de fulano". A associação de reiteração do comportamento à autoridade de um nome conhecido na "repartição" outorga o signo de adequação àquela conduta - e perde-se na poeira dos tempos as razões pelas quais esse mesmo "fulano" inaugurou a prática. Indagada porque age, a Administração, ciente de que a evocação do "fulano" pode não ser tão impactante fora dos seus próprios muros, não se revela capaz de objetivamente justificar - e por isso cala.

Já o temor do controlador é fenômeno já registrado na literatura (SUNDFELD, 2014, p. 43-44), mas tem especialmente no enfrentamento de ocorrências inéditas; do não usual (portanto, não regrado) uma causa de combate mais difícil. Manifestações novas de conflitos ou necessidade sociais se apresentam à Administração Pública, que é instada a oferecer algum tipo de resposta imediata - que justamente por essa celeridade que se lhe exige, é cunhada a partir de cenário parcial de conhecimento, num franco exercício de experimentalismo administrativo ${ }^{7}$. A par disso, a dinâmica que é própria à realidade sobre a qual incidem as políticas públicas determina necessariamente uma flexibilidade de parte da Administração Pública, de molde a realinhar os programas de ação ante uma mudança no cenário social que assim o exija - realinhamento esse que muitas vezes também envolve experimentar alternativas outras que não aquela já testada e revelada inadequada. Disso decorre que uma estratégia originalmente traçada pela Administração Pública não se deve ter por definitiva - seja porque ela revelava ab initio a precariedade que é própria do primeiro momento de resposta; seja porque a dinâmica dos fatos e das relações pode

\footnotetext{
7 Sustentando o caráter preferencial do desenvolvimento de políticas públicas através de decisões em
} múltiplos estágios, informada justamente pelo experimentalismo já havido (GUBLER, 2014). 
demonstrar a conveniência na reformulação do decidido. A reconfiguração do agir estatal não é de ser tida a priori como indicador de um erro original que se está apressadamente a corrigir - mas sim como ajustes naturais decorrentes do aprendizado incremental que se tem pela execução de políticas públicas.

Em que pese a justificativa lógica acima apresentada para algum grau de experimentação no âmbito da Administração Pública, fato é que subsiste a resistência em relação a este tipo de modelo (SABEL, 2011, p. 53), numa curiosa prática de negação teórica de um inequívoco dado da realidade nos órgãos públicos, no Brasil e alhures. O resultado é o ora denunciado desincentivo ao declínio das razões substantivas que orientaram a decisão inicial da Administração Pública.

Benefícios previsíveis da concepção de deferência ora proposta, que exige o conhecimento das razões que presidiram a ação administrativa são a revisitação do conhecimento tácito - que não obstante sua reiteração no órgão público, pode se revelar afinal inadequado ou obsoleto, movido mais pela inércia do que pela razão. Também no campo do experimentalismo, naturalizar o conhecimento parcial como possibilidade sempre presente à Administração, e com isso não mais se demonizar a experimentação, tendencialmente conduzirá a um double check a ser aplicado pelo agente da Administração quanto a se ter alcançado ao menos um patamar informacional mínimo, que autorize a decisão precária. Tem-se, portanto, na proposição ora veiculada um potencial elemento indutor de uma reflexão revisitada pela Administração Pública - ainda que no terreno pantanoso das decisões transitórias.

Superar essa opacidade é o primeiro estágio de aplicação de uma estratégia de deferência para com as escolhas públicas antecedidas do dever de planejamento. Mas não se resume nisso a proposição.

\subsection{Deferência como ferramenta de aferição da observância à autovinculação}

Se dinâmica é o traço marcante da ação administrativa, é de se ter em conta a possibilidade de que, não obstante a decisão estratégica inicial configuradora da política pública em curso, informada por força do primeiro estágio da deferência; a realidade evidencie uma não aplicação em concreto desta mesma escolha original. Esse fenômeno pode se creditar a duas distintas circunstâncias: 1) verificação no leito da aplicação, de que a escolha original se revelou inviável na perspectiva prática, ou 
inadequada na sua substância; e 2) patologia no plano da execução da política pública.

No último caso, a resposta é simples, e redunda no amplo espaço de atuação do controle para a recondução da ação administrativa aos termos em que ela foi concebida - e que não se revelou desautorizada pela realidade. O campo aqui é do controle da autovinculação ${ }^{8}$, eis que a Administração Pública, ciente de seus próprios deveres e possibilidades estabeleceu para si uma estratégia que se presume factível e que portanto, é de ser cumprida. O controle judicial, em situações que tais, não expressa atividade substitutiva do administrador, e não incide nos riscos de ausência de expertise - afinal, a solução fora concebida pela própria Administração, que dessa trilha não se poderia afastar, quando menos não sem reformular a sua decisão originária.

Já na primeira hipótese - evidência da inadequação da escolha original pela sua aplicação concreta - é de se investigar igualmente a apuração desses elementos reveladores do desacerto ou ineficácia da primeira opção; se esta alternativa inicial já se viu reconfigurada, e ainda qual a racionalidade a inspirar a nova orientação retificadora (se é que ela existe). Uma vez mais é de se registrar que a reorientação da ação administrativa em hipóteses que tais se revela consentânea não só com os imperativos da abertura à realidade e ao pensamento compatível com esse mesmo quadro fático ${ }^{9}$; como previne que a ação pública passe a se desenvolver no plano da administração paralela, denunciada por Gordillo (2001) como aquela que opera não a partir do sistema formal, excessivo e irrealizável, mas de um parassistema, clandestino, conhecido por poucos, e por isso mesmo, insuscetível de controle adequado.

Observe-se que a consideração da realidade, e a tradução formal de seus efeitos se alinha com o argumento de que diante da dinâmica inerente à ação pública e às políticas que a orientam, seja possível a reconfiguração estratégica. A contrapartida democrática e sob a perspectiva de controle desta mesma prerrogativa é a afirmação de dever de veiculação (sempre) da racionalidade que orientou o

\footnotetext{
8 Sustentando que o controle judicial de políticas públicas deva se desenvolver a partir do duplo referencial das determinações constitucionais (heterovinculações) e das escolhas livremente formuladas pela própria Administração Pública quando do desenho de suas estratégias de ação, consulte-se Valle (2016a).

${ }^{9}$ É de Rodríguez-Araña Munõz (2006) o registro de que a boa administração pressupõe um desempenho desta mesma função a partir de uma perspectiva de abertura à realidade sobre a qual ela incide, e de reação a esta mesma realidade em estratégias com ela consentâneas.
} 
redesenho do padrão de ação da Administração Pública. A virtude não está na imutabilidade da escolha, mas na capacidade de uma vez verificado o imperativo de sua correção, consignar as razões determinantes dessa mesma intervenção - seja na evidenciação do quid a reconfigurar, seja na identificação do novo curso de ação.

Mas se o critério de deferência como proposto não importa no bloqueio absoluto ao exercício do controle, resta clarificar quais os efeitos que o conhecimento das razões determinantes da ação estatal pode determinar sobre essa mesma atividade de crítica.

\subsection{Deferência como objetivação do controle: a dialética das racionalidades}

O terceiro estágio da aplicação do critério de deferência envolve a afirmação de que a crítica à escolha administrativa sob análise é de se dar a partir de uma perspectiva dialética com as razões da opção administrativa, à essa altura já conhecida. Essa proposição deita relevantes efeitos sobre o ônus argumentativo do agente controlador.

Duas são as aproximações usualmente empreendidas pelo controle quando do crivo da ação administrativa: ou se tem articulada uma pretensão puramente desconstitutiva (a escolha administrativa se reputa imperfeita, e por isso é de ser desconstituída); ou a ação controladora envolverá uma proposição substitutiva; a articulação de uma outra estratégia de ação que se reputa mais adequada do que aquela desenvolvida pela Administração. Numa e n'outra hipótese, o resultado é o afastamento da opção administrativa em curso a partir da perspectiva do controlador. Para bem compreender os limites do possível nesse tipo de ação corretiva, indispensável ter em conta a distinção de funções que se põe entre governo e controle.

É de Dromi (2005, p. 37) a referência ao papel do controle na estrutura hipermoderna do poder: assegurar qualidade e eficácia no seu exercício, para que aos que mandam não Ihes falte poder, e aos que obedecem, não lhes falte liberdade. Tem-se claro, portanto, uma relação de complementariedade - e não de superposição ou supremacia. Inexiste uma qualificação especial da perspectiva do controlador, que é de ser sempre e sempre, orientada pela Constituição, mas incidente sobre uma opção administrativa específica cuja apreciação é de ser parte integrante do juízo de adequação. 
Essa necessária referenciação já exclui como possibilidade um juízo de impugnação à ação administrativa que não dialogue com sua racionalidade original.

Segundo aspecto que respalda a lógica de uma necessária dialética com a fundamentação da decisão administrativa reside na circunstância de que em sociedades hipercomplexas, as alternativas estratégicas de ação postas ao Estado para a solução de um mesmo problema são múltiplas, sempre abertas à divergência e dissenso. O controle do poder, desejável garantia de efetividade dos compromissos finalísticos, é de se dar não a partir de um desacordo entre alternativas possíveis esposadas por cada qual dos integrantes da equação - mas a partir da evidenciação de que a escolha administrativa recai na zona de certeza negativa de possibilidades.

Não se cuida, portanto, de um duelo entre preferências estratégicas - mas da evidenciação de absoluta ausência de correspondência entre meios e fins na escolha perfilhada pela Administração Pública. Neste sentido, não basta o apontamento de parte do agente controlador de qual seja sua particular visão sobre a melhor estratégia; é preciso que antes disso se tenha objetivamente sustentada a incompatibilidade constitucional da escolha empreendida pela Administração Pública.

Se tudo se desenvolve a partir da argumentação racional (e outra não pode ser a inspiração da formulação e adequação das escolhas públicas), indispensável que o controle se desenvolva a partir de elementos objetivos - e isso exigirá uma dialética com as razões de decidir da Administração Pública, evidenciadas pelos dois estágios anteriores da aproximação deferente.

Essa é a compreensão que se deflui duplamente, da dicção do art. 20, Parágrafo Único, recentemente introduzido à Lei de Introdução às Normas do Direito Brasileiro pela Lei 13.655/18. O preceito determina, no caput, que não se decida "com base em valores jurídicos abstratos sem que sejam consideradas as consequências práticas da decisão". Disto se extrai o imperativo de especificação de conteúdo do valor jurídico abstrato em discussão, nisto se compreendo seus efeitos práticos. Significa dizer que escolha pública e sua correspondente crítica hão de ostentar a necessária relação entre meios (selecionados aplicar) e fins (constitucionalmente assinalados) - o que exclui qualquer possibilidade de argumentação unilateral, não dialógica.

A mesma conclusão decorre da leitura do Parágrafo Único do mesmo preceito, quando determina também às esferas controladora e judicial não só a motivação, mas que ela contenha a indicação da “...necessidade e a adequação da 
medida imposta ou da invalidação de ato, contrato, ajuste, processo ou norma administrativa, inclusive em face das possíveis alternativas". Tem-se no texto que a racionalidade controladora deverá envolver justificativa numa perspectiva crítico analítica (da necessidade e adequação da medida), mas também naquela comparativa (tendo em conta as alternativas possíveis). Evidentemente não se poderia estar pretendendo das instâncias controladoras um exercício de prospectiva de opções estratégicas que compreendessem outras possibilidades que não aquela efetivamente eleita pela Administração, e aquela que ao controlador se afigure como a mais adequada (seja lá qual for a origem deste juízo de adequação substitutivo à opção do Poder Público). Tem-se então, a partir da Lei 13.655/18, reforçada a necessária dialética da racionalidade a ser desenvolvida entre Administração e controle, nos termos da proposição que ora se apresenta de conteúdo a ser exigido da prática deferente.

A opção legislativa, é de se dizer, prestigia não só o exercício em si da função controle, mas a eficácia do sistema constitucional. Isso porque a ação equívoca da Administração é de ser objeto não de um juízo hermético de reprovação, mas de uma intervenção esclarecedora, que permita o aprendizado necessário ao realinhamento com os deveres constitucionais ${ }^{10}$. Completa-se, portanto, o quadro de aproximação deferente para com a escolha administrativa antecedida de planejamento quando se tem a sua eventual refutação dialogicamente construída, observadas as esferas possíveis de atuação de cada qual das estruturas institucionais. Também da identificação de zonas de certeza negativa se tem aprendizado institucional.

Já dos elementos de justificação do critério de deferência para com as escolhas administrativas como proposto, se extrai alinhamento com um projeto de efetivação dos compromissos constitucionais - portanto, sua plena viabilidade jurídica. Mas antes já se apontou que a proposição extrai seu fundamento não só do argumento em abstrato em favor da capacidade institucional da Administração - mas também da sua materialização em concreto na escolha investigada. É o que se passa a demonstrar.

\section{CAPACIDADES INSTITUCIONAIS, JUSTIFICAÇÃO E DEFERÊNCIA}

10 É de Medauar (2012, p. 30) a lição segundo a qual uma acepção ampla de controle deva compreender igualmente as aferições de conformidade da atuação da Administração Pública que não afetem, do ponto de vista jurídico, a decisão do agente. 
O debate em torno de capacidades institucionais - portanto, da indicação do peso e valor que a deliberação desta ou daquela estrutura de poder deva merecer, especialmente numa hipótese de conflito - tem como questão central a alocação de poder entre estas mesmas instituições. Não se cuida a rigor, de questão inteiramente original, eis que esse tema, não obstante presente desde os primórdios da organização das coletividades, tem sofrido constantes revisitações dado a evidente superação do velho esquema conceitual de especialização funcional como seu critério de equacionamento por excelência ${ }^{11}$.

Mais recentemente, essa mesma questão volta ao cenário, agora identificada pela expressão "capacidades institucionais", com acentuada inspiração no conhecido texto de Sunstein e Vermeule (2003) onde se refutavam esquemas teóricos identificadores do melhor método para o exercício da interpretação. Em apertadíssima síntese, os autores defendem a compreensão de que não há resposta em abstrato a esta indagação. Sua proposta é a "recalibragem" de velha pergunta, redirecionandoa para uma indagação acerca do modo segundo o qual certas instituições, com suas específicas habilidades e limitações, interpretam textos. Cada contexto fático, cada problemática apresentada à solução encontraria num determinado modo de interpretação do quadro normativo aplicável a melhor solução.

A identificação do método interpretativo adequado, na proposição dos autores, não repousa numa "teoria de autoridade" que proponha uma solução ótima de alocação de poder para todos os casos. A ideia de uma first-best solution a ser ofertada sempre segundo um determinado esquema interpretativo típico da instituição "a" ou "b" é apontada como insuficiente, eis que desconsidera as aptidões e limites institucionais dos atores envolvidos, e os possíveis efeitos dinâmicos da resposta ofertada à hipótese por cada qual deles. Uma escolha interpretativa que tenha em conta as capacidades institucionais pode eventualmente ter por possível uma secondbest solution - second-best não porque abdique de um resultado ótimo possível, mas porque incorpora um espectro de análise que compreende não só resultados presentes, mas também os chamados efeitos dinâmicos da decisão.

Os riscos de má utilização desta compreensão foram objeto de análise por Arguelhes e Leal (2011, p. 17), que enfatizaram o equívoco em se pretender aplicar o

\footnotetext{
11 É conhecido o texto de referência de Ackerman (2010, p. 128-133), que propõe o abandono do esquema explicativo de Montesquieu, tendo em conta a eclosão de outras estruturas de organização do convívio coletivo.
} 
argumento a partir de uma perspectiva apriorística ou abstrata - que é refutada, como premissa, pelos próprios autores. É nesse contexto que a proposta ora delineada de deferência para com as escolhas administrativas não se esgota na identificação de parte do agente controlador do autor da escolha pública. A se adotar essa aproximação, estar-se-ia incidindo no equívoco que Arguelhes e Leal (2011, p. 17) denominam de uso redundante da categoria.

A deferência, nos termos da formulação que ora se apresenta, tem lugar como critério orientador do exercício do controle das capacidades institucionais, quando se cuide de decisão administrativa antecedida do exigível dever de planejamento. É só no exercício dessa formulação estratégica que se pode ter indícios de que a capacidade institucional presumida em favor da Administração Pública foi efetivamente aplicada na eleição da linha de ação a ser desenvolvida, a partir da interpretação do quadro normativo vigente.

Compreende-se na aproximação deferente preconizada neste texto, o exercício da crítica à opção administrativa numa relação dialética com essa mesma escolha. Elege-se um caminho em favor da análise comparativa entre estratégias que estão competindo entre si - aquela formulada pela Administração, e aquela que se apresenta como a mais adequada pelo agente controlador.

O exercício do controle a partir deste diálogo de racionalidades tem-se ainda por exigível quando se tem em conta os chamados efeitos dinâmicos da decisão. Uma vez mais é de Sunstein e Vermeule (2003, p. 900) o apontamento de que a aproximação judicial não terá seus efeitos limitados às partes envolvidas, ou nem mesmo ao sistema de adjudicação. O efeito "teia de aranha" (FULLER e KENNETH, 1978) ${ }^{12}$ incrementa exponencialmente as dificuldades de predição dos efeitos da intervenção judicial nas escolhas administrativas, e por isso também a questão das capacidades institucionais se afigura como relevante - quando menos para a necessária prospecção dos resultados possíveis, inclusive os negativos.

Por último - mas não menos importante - é de se apontar o papel que a deferência para com as escolhas administrativas antecedidas do dever de planejamento tem no robustecimento da justificativa, tanto da ação pública, quanto da intervenção controladora. Dúvida não pode haver em relação ao dever de motivação de ambas as condutas, ex vi dos arts. 37, caput e 93, IX CF. O que se põe como

${ }^{12}$ FULLER, Lon L., e KENNETH I. Winston. The forms and limits of adjudication. Harvard Law Review, 92, no. 2 (1978): 353-409. 
componente novo, especialmente no campo da ação pública, é a aguda percepção de que o elemento de justificação, antes confortavelmente assentado na lógica da legalidade estrita, hoje não se põe mais como disponível a todas as escolhas perpetradas pelo poder.

Fundar uma ordem jurídica em valores e direitos fundamentais é atrair para ela algum grau de indeterminação - e isso não é um vício, mais uma virtude que preserva a resiliência do sistema. Se os grandes vetores de constrição das decisões políticas abrem-se ao permanente exercício de determinação de sentido; fato é que nem sempre as escolhas públicas encontrarão suporte direto na cristalização jurídica ofertada pela legalidade. É a captação política dos interesses da sociedade (MOREIRA NETO, 2002, p. 15) que permitirá a aferição dos sucessivos níveis de consenso mínimo alcançado em relação a determinados propósitos constitucionais que se traduzirão por sua vez, na perspectiva da pura operacionalização do poder, em políticas públicas e escolhas administrativas diversas. Desponta neste cenário, a relevância da prevenção quanto ao caos decisionista, ou ainda da dissociação entre justificação (formal) e motivação (real) (FREITAS, 2017). Isso só se logrará alcançar com um critério de aferição controladora que a um só tempo, exija a motivação, mas ainda a prestigie como fio condutor da discussão em torno do acerto da escolha empreendida pela Administração.

Vale consignar por derradeiro, que esta lógica de prestígio à racionalidade administrativa se insere num contexto em que desmistificados os esquemas simplificadores das escolhas do poder, tem-se cada vez mais claro que o foco do controle é de recair não na forma, mas na substância. É certo que a proposta desafia dificuldades, em especial, o problema da informação, que compreende uma empiria apta a corroborar a proclamação da capacidade institucional (ARGUELHES e LEAL, 2016). Não é menos certo, porém, que a negação dos obstáculos tampouco se afigura como alternativa de solução.

\section{PRÓXIMOS PASSOS}

Não se anima esta escriba a ultimar estas considerações com o epíteto de conclusão. Antecipou-se na parte introdutória que aqui se tem uma pesquisa em andamento, e que o principal objetivo é ampliar o debate em torno de uma alternativa de correção dos desvios de percurso que o sistema de controle culminou por adotar. 
O conceito proposto de aproximação deferente se afasta da lógica da insindicabilidade das escolhas administrativas - resultado que já se apontou, é de difícil sustentação no ambiente democrático inaugurado pela Carta de 1988. De outro lado, sua tríplice dimensão de nivelamento cognitivo, investigação quanto à fidelidade à auto-vinculação e provocação a uma dialética de racionalidades no exercício do controle favorece o expurgo de análises subjetivas, que em nada contribuem para o ideal de estabilidade de previsibilidade que é inerente à segurança jurídica. Com isso, tem-se por evidenciada a possibilidade constitucional de um controle judicial que revele, em relação às escolhas administrativas, uma aproximação deferente - sem que com isso se tenha qualquer arranhão à garantia constitucional de acesso à justiça.

Passo subsequente no desenvolvimento da pesquisa será a identificação dos atributos que se deva exigir da formulação administrativa da escolha, para que nela se possa identificar efetivamente uma ação planejada, suscetível em tese de aferição a partir do critério de deferência. Não resta dúvida que a apreciação dos possíveis efeitos das opções administrativas é componente hoje inafastável do perfil de uma ação planejada, ante os reclamos agora normatizados pela Lei $13.655 / 18$. Outros componentes, todavia, hão de se somar para que se tenha como aplicável a defendida aproximação controladora deferente.

Todos os componentes a amparar a proposição da deferência para com as opções administrativas planejadas indicam a necessidade de procedimentalização da escolha, definindo-se etapas indispensáveis à garantia de que os componentes orientadores da decisão vieram à luz. É no desenho procedimento que se poderá investir no aprofundamento da justificativa, componente central para que se reconheça legitimidade de escolhas administrativas cada vez mais complexas, cujos efeitos se prolongam no tempo e no espaço. Uma vez mais, não se pode pretender operar com alternativas simplificadoras, que pretendam através de um desenho único, oferecer resposta a toda a miríade de decisões que a função administrativa formula. A complexidade é inerente ao ordenamento do convívio e à satisfação das expectativas coletivas, porque o homem não é simples. Buscar a simplificação aqui é operar a partir de um ser humano ideal - e soluções traçadas puramente no campo do ideal tendem a determinar tão-somente frustrações.

\section{REFERÊNCIAS BIBLIOGRÁFICAS}


ACKERMAN, Bruce. Good-bye, Montesquieu. Comparative Administrative Law (2010): 128-133.

ARGUELHES, Diego Werneck e LEAL, Fernando. O argumento das "capacidades institucionais" entre a banalidade, a redundância e o absurdo. Direito, Estado e sociedade. Rio de Janeiro, $n^{\circ} 38$, jan-jul 2011, p. 6-50.

ARGUELHES, Diego Werneck e LEAL, Fernando. Dois problemas de operacionalização do argumento de capacidades institucionais. in BOLONHA, Carlos, BONIZZATO, Luigi e MAIA, Fabiana. Teoria institucional e constitucionalismo contemporâneo. Curitiba: Juruá Editora, 2016, p. 565-578.

BARROSO, Luís Roberto. Judicialização, Ativismo Judicial e Legitimidade Democrática. (Syn)Thesis, Vol. 5, nº 1, 2012, p. 23-32.

BOBBIO, Norberto. Teoria geral da política. A filosofia política e as lições dos clássicos. $9^{a}$ reimp., tradução Daniela Beccaccia Versiani. São Paulo: Elsevier Editora, 2000, p. 386, 717 p.

CHEVALLIER, Jacques. O Estado pós-moderno. Tradução, Marçal Justen Filho. Belo Horizonte: Editora Fórum, 2009.

DROMI, Roberto. El derecho publico em la hipermodernidad. Madrid: Editorial Hispania Libros, 2005.

DROMI, Robert. Modernización del control público. Madrid - México: Hispania Libres. 2005.

FREITAS, Juarez. The hidden sido of the legal decisio and duty of justification. Revista de Estudos Constitucionais, Hermenêutica e Teoria do Direito (RECHTD), 9 (3), 2017, p. 240-249.

FULLER, Lon L., e KENNETH I. Winston. The forms and limits of adjudication. Harvard Law Review, 92, no. 2 (1978): 353-409.

GORDILLO, Agustín A. La administración paralela.3ª reimp., Madrid: Civitas, 2001.

GUBLER, Zachary J. Experimental Rules. Boston College Law Review, Boston, Vol. 55,2014 , p. 129-179.

HASEN, David M. The Ambiguous Basis of Judicial Deference to Administrative Rules. Yale Journal on Regulation, New Haven, Vol. 17 (2000): 327-366.

JORDÃO, Eduardo. Controle judicial de uma Administração Pública complexa. A experiência estrangeira na adaptação da intensidade do controle. São Paulo: Malheiros Editores, 2016.

MARQUES NETO, Floriano de Azevedo. Os grandes desafios do controle da Administração Pública. Fórum de Contratação e Gestão Pública - FCGP, Belo Horizonte, ano 9, n. 100, abr. 2010. Disponível em: 
<http://www.bidforum.com.br/bid/PDI0006.aspx?pdiCntd=66621>. Acesso em: 9 de julho de 2018.

MEDAUAR, Odete. Controle da Administração Pública. $2^{a}$ ed., rev., atualizada e ampliada, 2012.

MORAES, Germana de Oliveria. Controle jurisdicional da Administração Pública. São Paulo: Dialética Editora, 1999.

MOREIRA NETO, Diogo de Figueiredo. Legitimidade e discricionariedade. Novas reflexões sobre os limites e controle da discricionariedade. $4^{a}$ ed., Rio de Janeiro: Editora Forense, 2002.

MOREIRA NETO, Diogo de Figueiredo. Novo referencial no Direito Administrativo: d o controle da vontade ao do resultado: a juridicização dos resultados na Administração Pública. Fórum

Administrativo - Direito Público - FA, Belo Horizonte, ano 6, n. 67, set. 2006, p. 44-

56. Disponível em:<http://www.bidforum.com.br/bid/PDI0006.aspx?pdiCntd=37401>. Acesso em 9 de julho de 2018.

MOREIRA NETO, Diogo de Figueiredo. Novas mutações juspolíticas. Em memória de Eduardo García de Enterría, jurista de dois mundos. Belo Horizonte: Editora Forum, 2016.

RODRÍGUEZ-ARAÑA MUÑOZ, Jaime. El buen gobierno e la buena administración de instituciones publicas. Adaptado a la Ley 5/2006, de 10 de abril. Thomson Aranzadi, 2006

SABEL, Charles F., e WILLIAM H. Simon. Minimalism and experimentalism in the administrative state. Georgetown Law Journal, 100 (2011): 53.

SCALIA, Antonin. Judicial deference to administrative interpretation of law. Duke Law Journal, Volume 1989, Number 3, p. 511-521.

SUNDFELD, Carlos Ari. Direito Administrativo para céticos. $2^{\mathrm{a}}$ ed., rev. e ampl., Sâo Paulo: Malheiros Editores, 2014.

SUNSTEIN, Cass e VERMEULE, Adrian. Interpretation and institutions. Michigan Law Review 101, no. 4 (2003): 885-951.

UNITED STATES OF AMERICA. Supreme Court of the United States of America. Chevron U.S.A., Inc. v. Natural Resources Defense Council, Inc., 467 U.S. 837. Disponível em https://supreme.justia.com/cases/federal/us/467/837/, acesso em 10 de julho de 2018.

VALLE, Vanice Regina Lírio do. Políticas públicas, controle judicial e direitos fundamentais. $2^{a}$ ed., rev. e ampl., Belo Horizonte, Editora Fórum, 2016a.

VALLE, Vanice Regina Lírio do. Demandas derivadas e ampliação do núcleo essencial 
do direito à moradia: deferência como critério judicial de solução. in: José Ribas Vieira; Margarida Maria Lacombe Camargo; Rogerio Barros Sganzerla. (Org.). Direitos fundamentais e jurisdição constitucional. Belo Horizonte: Editora Forum [on line], 2016b, p. 182-208.

VALLE, Vanice Regina Lírio do. Deferência como efeito jurídico da ação pública planejada. in: LEITE, George Salomão, STRECK, Lenio e NERY JUNIOR, Nelson. (Org.). Crise dos poderes da república: judiciário, legislativo e executivo. São Paulo: Editora Revista dos Tribunais, 2017, p. 931-947.

Recebido em 03/05/2019

Aprovado em 30/03/2020

Received in 03/05/2019

Approved in 30/03/2020 